\title{
Relationship between Hearing Impairment and Cognitive, Functional and Psychosocial Status of Community Dwelling Older Adults
}

\author{
Naglaa Alsaied Mostafa Alfauomy, Demonstrator \\ Gerontological Nursing, Faculty of Nursing, Damanhur University
}

Hanaa Shafik Ibrahim, Assistant Professor

Gerontological Nursing, Faculty of Nursing, Alexandria University

Samia Khattab Abd-Alrahman, Assistant Professor

Gerontological Nursing, Faculty of Nursing, Damanhur University

Reham Magdy Mohamed Abd-EI Salam, Lecturer

Gerontological Nursing, Faculty of Nursing, Alexandria University

\begin{abstract}
Hearing impairment is a common health problem affecting older adults and its prevalence increases with age. It had a significant effect on all aspects of life of older adults. Objective: This study aims to identify identify the relationship between hearing impairment and cognitive, functional and psychosocial status of community dwelling older adults. Setting: The study was conducted in the Ear, Nose and Throat (E.N.T) Outpatient clinic of Damanhur National Medical Institute El-Behaira Governorate, Egypt. Subjects: All older adults attending the outpatient clinic at the time of the study were included in the study. Their number amounted to 200 older adults. They were divided randomly into two equal groups study group $(n=100)$ and control group $(n=100)$. Tools: Socio-demographic and clinical data of the older adults with hearing impairment structured interview schedule, The Mini-Mental State Examination (MMS), Barthel Index Scale, Lawton and Brody scale, The General WellBeing Schedule and UCLA Loneliness Scale (version 3). Results: A statistical significant difference was observed between both groups as regards cognition, performance of IADLs and psychosocial status while no significant difference was found concerning performance of ADLs. Conclusion: Hearing impairment is associated with mild cognitive impairment, severe psychological disturbance and moderate loneliness. Also, performance of IADLs is affected while ADLs is not affected. Recommendations: Teach older adults with hearing impairment about the importance of using hearing aids. This will help to improve their cognitive, functional and psychosocial status. Encourage older adults with hearing impairment to do annual ear examination to prevent further deterioration.
\end{abstract}

Keywords: Hearing impairment; Cognitive; Functional; Psychosocial status; Older adults.

\section{Introduction}

Hearing impairment is one of the most prevalent chronic sensory conditions in older adults ${ }^{(1,2)}$. It is reported by one third of the world's older adults $(33 \%)^{(3)}$. In USA, 30 million persons suffered from hearing impairment and older adults constituted one third of them ${ }^{(4,5)}$. In Egypt (2007), hearing impairment was reported to affect half of older adults 65 years or more $(49.3 \%)^{(6)}$. In Alexandria (2009), hearing impairment was reported by $55.5 \%$ of institutionalized older adults ${ }^{(7)}$. This percent increased to $78.6 \%$ among hospitalized older adults in Alexandria Main University Hospital in $2012^{(8)}$. In Damanhur, about $30.5 \%$ of older adults attending the Ear, Nose and Throat (E.N.T) Outpatient Clinic of Damanhur National Medical Institute at El-Behaira Governorate during (2014) suffered from hearing impairment ${ }^{(9)}$.

Types of hearing impairment in older adults include Conductive, sensorineural 
and mixed hearing impairment ${ }^{(4,10)}$. Conductive hearing impairment occurs when conditions in the outer or middle ear impair the transmission of sounds through air to the inner ear. Sensorineural hearing impairment results from trauma or disease to inner ear, nerve pathways or vestibular cochlear nerve which leads to have the ability to hear sound but not to understand speech $^{(11,12)}$. Age related hearing impairment (presbycusis) is considered a type of sensorineural hearing impairment. Presbycusis is a progressive and irreversible bilateral symmetrical hearing impairment resulting from age related changes in inner ear. It initially affects the higher frequencies before progressing to the lower frequencies $^{(5,7)}$. While mixed hearing impairment is a combination of conductive and sensorineural hearing impairment ${ }^{(11,12)}$.

Causes of hearing impairment in older adults are numerous. They include exposure to excessive noise, age related changes of the inner ear, ototoxic medications (e.g., high doses of aspirin), high blood pressure, head trauma, smoking, auditory nerve tumour and genetic factors ${ }^{(11-13)}$.

Hearing is important for socialization, communication and protection from potential danger. This is particularly true for older adults. Also, older adults can be empowered and kept in contact with the outside world through hearing ${ }^{(14-16)}$. Exchange of information with others, an important aspect of everyday life, can be seriously impaired if the older adults suffer from hearing impairment. This may lead to social isolation, maladjustment, anxiety, depression, low self-esteem, loneliness, frustration, poor relationships with family and friends and less engagement in preferred activities. Hearing impairment may threaten older adults' safety by putting them at risk to accident and understanding verbal health care instructions. This in turn, will lead to a perceived reduction in quality of life $\mathrm{e}^{(10,17-19)}$.

Hearing impairment is serious because not only does it affect the physical sense of hearing, but it also affects overall well-being ${ }^{(17,20)}$. In the United States, a study conducted in (2003) reported that hearing impairment in older adults restrict multiple dimensions of quality of life, including functional status, cognitive, emotional, and social function ${ }^{(21)}$.

Many older adults are aware that their hearing has deteriorated but are reluctant to seek help, perhaps they don't want to acknowledge the problem or are embarrassed by what they see as a weakness $^{(22)}$. So, the gerontological nurse should focus on the cognitive, functional and psychosocial status of older adults suffering from hearing impairment and its effect on their health ${ }^{(11,18,23)}$.

\section{Aim of the Study}

This study aims to identify the relationship between hearing impairment and cognitive, functional and psychosocial status of community dwelling older adults.

\section{Research Question:}

What is the relation between hearing impairment and cognitive, functional and psychosocial status of community dwelling older adults?

\section{Materials and Method}

\section{Materials}

Design: A case-control research design.

Setting: The study was conducted in the Ear, Nose and Throat (E.N.T) outpatient clinic of Damanhur National Medical Institute, El-Behaira Governorate.

Subjects: The study subjects comprised 200 older adults attending the previously mentioned setting and fulfilling the following criteria: age 60 years and above, free from neurological disorders such as stroke or Parkinson's disease, not using hearing aids and free from fracture that hinder functional abilities. They were assigned randomly by age and sex into two equal groups of 100 each. The study group $(n=100)$ included older adults diagnosed 
with hearing impairment and the control group $(n=100)$ are those diagnosed with other ENT disorders rather than hearing impairment.

Tools: In order to collect the necessary data, six tools were used:

Tool I: Socio-Demographic and Clinical Data of Older Adults with Hearing Impairment Structured Interview Schedule

This tool was developed by the researcher and included three parts:

- Part 1: Socio-demographic characteristics of the elders such as age, sex, marital status, educational level, residence and income.

- Part 2: Health profile of the elders: it included questions related to hearing impairment for the study group and health history for both groups.

- Part 3: Social activities such as visits and phone calls to relatives or friends for both groups.

\section{Tool II: The Mini-Mental State Examination (MMS)}

It was developed by Folstein et al. $(1975)^{(24)}$. It was used to assess cognitive function of the subjects. It includes questions related to orientation, registration, attention, calculation, recall and language.

The MMS scale score is 30 points and is classified as follows:

- Score 0-17 indicates severe cognitive function impairment.

- Score 18-23 indicates mild cognitive impairment.

- Score 24-30 indicates normal cognitive function.

The MMS scale was translated into Arabic language by Elokl (2002) and proved to be valid and reliable ${ }^{(25)}$. Reliability coefficient for this tool was $\mathrm{r}=0.93$.

Tool III: Barthel Index Scale (BI)
It was developed by Barthel et al. $(1965)^{(26)}$. This tool was used to assess elder's activities of daily living. It consists of 10 items namely feeding, dressing, bathing, toileting, controlling bladder, controlling bowel, moving from chair to bed and return, getting on and off toilet, walking on level surface, ascend and descend stairs. The total score of the scale is 20 classified as follow:

- Score 0-7 indicates dependent.

- Score 8-12 indicates partially dependent.

- Score 13-20 indicates independent.

The (BI) was translated to Arabic language by Hallaj (2007) and proved to be valid and reliable ${ }^{(27)}$. Reliability of the tool was tested using test-retest reliability spearman's coefficient $r=0.971$.

Tool IV: Instrumental Activities of Daily Living "Lawton and Brody Scale"

Lawton and Brody Scale (1969) ${ }^{(28)}$ was used to assess instrumental activities of daily living. It includes eight items; the ability to use telephone, shopping, food preparation, house-keeping, laundry, transportation, responsibility for own medication and ability to handle finances. The range of score of the scale is from 8-24. The score is classified into three categories as follow:

- Score from 8 to 12 indicates that inability to perform the activity.

- Score from 13 to 20 indicates that the activity is performed with some help.

- Score from 21 to 24 indicates that the activity is performed unaided.

It was translated to Arabic language by Elsayed (2007) and proved to be valid and reliable ${ }^{(29)}$. Reliability of the tool was tested by Cronbach's coefficient alpha $\mathrm{r}=0.83$.

\section{Tool V: The General Well-Being} Schedule

It was developed by Dupuy $(1977)^{(30)}$.

It was used to measure feelings of 
psychological well-being and distress of older adults in community. It includes 18 items measuring six dimensions namely positive well-being, self-control, vitality, anxiety, depression and general health. A total score is running from 0 to 110 and can be classified to the following scores ${ }^{(31)}$ :

- Scores of 0 to 60 reflect severe distress.

- Scores of 61 to 72 reflect moderate distress.

- Scores of 73 to 110 reflect positive wellbeing.

\section{Tool VI: UCLA Loneliness Scale (version} 3)

It was developed by Russell et al. $(1987)^{(32)}$. It was used to assess feeling of loneliness in middle-aged and older adults. It includes 34 statements. It was translated to Arabic language by Kashkoush $(1988)^{(33)}$. The total score is adjusted from 1 to 136and can classify the result to the following scores:

- Score equal to 34indicates not lonely.

- Score from 35 to 67 indicates mild loneliness.

- Score from 68 to 101 indicatesmoderate feeling of loneliness.

- Score from 102 to 135 indicates severe loneliness.

- Score equal to 136indicates extreme loneliness.

\section{Method}

- Official letter was issued from the Faculty of Nursing, Alexandria University and forwarded to the head of the study setting of Damanhur National Medical Institute at El-Behaira Governorate to obtain his assistance and approval to carry out the study.

- Tool I (socio-demographic and health profile structured interview schedule was developed by the researchers.

- The Arabic version of tools II, III, IV and VI were used in this study.
- Tool V was translated into Arabic language by the researcher. This tool was tested for content validity by seven experts in the related fields.

- Reliability of tool V and VI were tested by using Cronbach's coefficient alpha test. It was applied to 20 elderly patients with hearing impairment who fulfilled the inclusion criteria and those patients were not included in the study subjects. The reliability result for tool $\mathrm{V}$ was $\mathrm{r}=0.92$ and tool VI was $\mathrm{r}=0.94$.

- A pilot study was carried out on 10 elderly patients(those patients were not included in the study subjects)selected from Dar El Saada elderly home in Damanhur Governorate to assess for the applicability and clarity of the tools, also to estimate the approximate time needed to complete the study tools.

- Older adult patients attending E.N.T clinic and fulfilling the inclusion criteria were included in the study. Those diagnosed with hearing impairment by the physician were assigned to the study group. While those diagnosed with other ENT disorders than hearing impairment were assigned to the control group by using matching by age and sex until the number of study subjects is reached.

- The interview time ranged from 30 to 45 minutes for the study group (suffering from hearing impairment and required frequent repetition) and from 15 to 25 minutes for the control group to complete the study tools according to the level of understanding and cooperation of the study subjects.

- The data collection covered a period of four months from the beginning of March till the end of June 2016.

\section{Ethical considerations:}

Verbal consent was obtained from each participant in the study after explanation of the study purpose. Each participant was assured about the confidentiality of the 
collected data. The privacy and anonymity of each participant was maintained.

\section{Statistical Analysis}

The statistical package for social science (SPSS) was utilized for data analysis and tabulation. The level of significance selected for this study was "P" equal or less than 0.05 .

\section{Results}

Table (1) shows the distribution of older adults in the study and control groups according to their socio demographic characteristics. The mean age of the study subjects is $70.58 \pm 8.264$ years and $69.29 \pm 8.260$ for the control group. Males were more prevalent than females; they constituted $57.0 \%$ and $43.0 \%$ respectively in both groups. As regards marital status, $53.0 \%$ and $62.0 \%$ respectively for the study and control groups were married. No significant difference is observed between both groups regarding age, sex and marital status.

Concerning educational level, $59.0 \%$ and $58.0 \%$ of both the study and control groups are illiterates. The mean monthly income for both the study and control groups was $516.88 \pm 292.80$ and $599.94 \pm 299.49$ respectively. No significant difference is noted between both groups regarding level of education but a significant difference is found between both groups regarding income.

Table (2) shows distribution of older adults in the study and control groups according to their health history. Concerning the medical diseases, the table shows that $53.0 \%$ and $44.0 \%$ respectively of both the study and the control groups suffer from cardiovascular diseases followed by ophthalmological diseases $(32.0 \%$ and $38.0 \%)$, diabetes mellitus $(20.0 \%$ and $35.0 \%)$, GIT \& hepatic diseases $(12.0 \%$ and $13.0 \%)$ and respiratory diseases $(10.0 \%$ and $4.0 \%$ ) respectively of both the study and the control groups. No significant difference is found between both groups for all medical diseases except diabetes mellitus.

Regarding consumption of medication, it is noticed that $47.0 \%$ and $42.0 \%$ of both the study and the control groups respectively consume cardiovascular drugs followed by diabetic drugs $(19.0 \%, 33.0 \%)$, GIT \& hepatic drugs $(12.0 \%$ and $13.0 \%)$ and respiratory drugs $(10.0 \%, 13.0 \%)$ for both groups. No significant difference is found between both groups for all drugs except respiratory and diabetic drugs.

It is observed that $31.0 \%$ and $14.0 \%$ of both the study and control groups respectively reported family history of hearing impairment. A significant difference is found between both groups.

Table (3) shows the distribution of older adults in the study and control groups according to their social activities. A significant difference is noted between both groups concerning participation in social activities such as visiting outside home $(\mathrm{P}=0.001)$, phone call $(\mathrm{P}=0.001)$, watching $\mathrm{TV}$ or listening to radio $(\mathrm{P}=0.004)$ and preference to sit alone $(\mathrm{P}=0.002)$. The main cause for non-participation in social activities for the study group was hearing impairment.

Table (4) shows the distribution of older adults suffering from hearing impairment according to their history of hearing impairment. The duration of hearing impairment ranged from one to more than 15 years with a mean of $8.36 \pm 6.25$ years. More than two third $(69.0 \%)$ of the study group had sensorineural hearing impairment, while the rest had either conductive hearing impairment $(29.0 \%)$ or mixed hearing impairment (2.0\%). Regarding the affected ear, it was noticed that $60.0 \%$ of the study group suffered from bilateral hearing impairment, $23.0 \%$ suffered from hearing impairment in left ear and the rest $(17.0 \%)$ in right ear.

Table (5) illustrates the relation between cognitive, functional and psychosocial status of older adults with hearing impairment and their controls. It is found 
that $39.0 \%$ and $17.0 \%$ of both the study and the control groups had mild cognitive function impairment, $7.0 \%$ and $3.0 \%$ of both groups had severe cognitive function impairment, and $54.0 \%$ and $80.0 \%$ of both the study and the control groups had normal cognitive function. A statistical significant difference is observed between both groups $(\mathrm{P}=0.001)$.

In relation to performance of activities of daily living, $95.0 \%$ and $94.0 \%$ of both the study and the control groups were independent, $4.0 \%$ and $6.0 \%$ of both groups need assistance and $1.0 \%$ of the study group and none of the control group were totally dependent. There is no statistical significant difference between both groups $(\mathrm{P}=0.594)$. While concerning instrumental activities of daily living $44.0 \%$ and $36.0 \%$ of both the study and the control groups were unable to perform instrumental activities of daily living, $41.0 \%$ and $35.0 \%$ of both groups need assistance and $15.0 \%$ and $29.0 \%$ of both the study and the control groups perform activities unaided. A statistical significant difference between both groups was noted $(\mathrm{P}=0.048)$.

Concerning psychological status, $42.0 \%$ and $9.0 \%$ of both the study and the control groups had severe distress, $25.0 \%$ and $18.0 \%$ of both groups had moderate distress and $33.0 \%$ and $73.0 \%$ of both the study and the control groups had positive well-being. A statistical significant difference was noted between both groups $(\mathrm{P}=0.001)$.

Concerning social status, $60.0 \%$ and $23.0 \%$ of both the study and the control groups suffer from moderate loneliness, $22.0 \%$ and $1.0 \%$ from severe loneliness and $14.0 \%$ and $74.0 \%$ from mild loneliness. While $3.0 \%$ of the study group and none of the control group showed extreme loneliness, and $1.0 \%$ and $2.0 \%$ of both groups were not lonely. A statistical significant difference was found between both groups $(\mathrm{P}=0.001)$.

\section{Discussion}

In the present study, more than one third of older adults with hearing impairment had mild cognitive impairment compared to one fifth of their controls. A significant difference was found (table 5). Mild cognitive impairment can be a warning sign to severe cognitive impairment especially if there are other factors that contribute to the occurrence of this problem as reported in the present study that one quarter of older adults suffering from hearing impairment didn't watch TV or listen to radio and prefer to sit alone and more than half of them isolate themselves from others and didn't do phone call or visit outside home (table 3). The result of the present study is in line with the finding of the study done by Lin et al. (2013) ${ }^{(34)}$ who reported that hearing impairment is associated with accelerated cognitive decline and incident cognitive impairment.

In relation to functional ability of older adults suffering from hearing impairment, no significant relation was observed between the ability to perform ADLs and hearing impairment (table 5). This can be justified as performance of ADLs depends on intact motor function of older adults rather than the ability to interact and communicate with others. In addition, the present study excluded those suffered from orthopedic diseases that interfere with the ability of older adults to function well.

In contrast, a significant relation was noted in the present study between hearing impairment and the ability of older adults to perform IADLs (table 5). This can be interpreted as performance of some areas of IADL such as shopping and using the telephone need communication and interaction with others which is hindered by hearing impairment. This result is in line with the findings of other studies done by Crispim et al. (2015) ${ }^{(35)}$.

In the present study, a significant relation between hearing impairment and psychological status was documented (table 5 ). This result was supported by what was 
reported by older adults themselves as they had low self-esteem, feeling anger and suspicious. Also, the stigma associated with hearing impairment and the attitudes of others, together with one's own perceptions, can accelerate feeling of psychological problem $^{(36)}$. This result is in line with the findings of other studies done by Boorsma et al. (2012) in Germany ${ }^{(37)}$, and Acar et al. (2011) in Turkey ${ }^{(38)}$.

In the present study about two thirds of older adults with hearing impairment suffered from moderate loneliness compared to about one quarter of the control group. A significant difference was found between both groups (table 5). This result is in line with what was stated by older adults suffering from hearing impairment as more than one third of them feel embarrassed when talking with others for the first time, more than one quarter of them reported their preference to sit alone and more than half of them isolate themselves from others (table 3). Older adults suffering from hearing impairment may be neglected during conversation with others as communication requires loud voice and frequent repetition that need more time, effort and disturb others. Thus people try to avoid them. This result supports that of Mick et al. (2014) in $\mathrm{USA}^{(39)}$ who reported that hearing impairment was associated with social isolation.

In the present study the main factors having a significant relation with hearing impairment in older adults were low income, consumption of respiratory drugs and positive family history.

The present study revealed a significant difference between both groups regarding income (table1). This may be due to low income limits resources for health promotion, health services and periodic medical check-up. Thus it hinders early detection of the disease. This result is in line with the findings of a study done by Stevens et al. (2013) who reported that hearing impairment is positively related to low- and middle-income ${ }^{(41)}$.
Respiratory drugs are considered a risk factor for hearing impairment (table 2). This may be explained by most of respiratory drugs are glucocorticosteroids and antibiotics which are considered ototoxic drugs that decrease hearing acuity ${ }^{(40)}$. This result is supported by study done by Schacht et al. (2012) who reported that some antibiotics have the potential to cause sensorineural hearing impairment ${ }^{(42)}$.

Also, a significant difference regarding family history was found between both groups (table 2). This result is in line with the finding of a study done by Sogeb et al. $(2013)^{(43)}$.

\section{Conclusion}

It can be concluded from the present study that hearing impairment had significant effect on cognition, performance of IADLs and psychosocial status of older adults. Older adults who suffer from hearing impairment have mild cognitive impairment, severe psychological disturbance, suffer from loneliness and are unable to perform IADLs while ADLs were not affected.

\section{Recommendations}

The main recommendations are:

- Older adults suffering from hearing impairment should be encouraged to use hearing aids and follow annually the progress of their condition.

- Encouragement of older adults with hearing impairment and their families to participate in rehabilitation program which include auditory training, speech and reading training and communication techniques such as reduce background noise, use facial expression or gestures and talk toward the better ear. 
Hearing Impairment: Cognitive, Functional and Psychosocial Status

- Encouragement of older adults with hearing impairment to participate in social activities and recreational activities through exploring type of activities, hobbies and interests that are satisfying to the older adults and encourage continued involvement and participation in group activity. 
Table (1): Distribution of older adults in the study and control groups according to their socio demographic characteristics

\begin{tabular}{|c|c|c|c|c|c|}
\hline \multirow{3}{*}{ Socio demographic data } & \multicolumn{4}{|c|}{ Group } & \multirow{3}{*}{$M C P$} \\
\hline & \multicolumn{2}{|c|}{ Study } & \multicolumn{2}{|c|}{ Control } & \\
\hline & $n=100$ & $\begin{array}{c}\text { Percent } \\
(\%)\end{array}$ & $\mathrm{n}=\mathbf{1 0 0}$ & $\begin{array}{c}\text { Percent } \\
(\%)\end{array}$ & \\
\hline Age (in years): & & & & & \\
\hline$\overline{-60-}$ & 64 & 64.0 & 64 & 64.0 & \\
\hline$-75-$ & 26 & 26.0 & 26 & 26.0 & 1.000 \\
\hline$-85+$ & 10 & 10.0 & 10 & 10.0 & \\
\hline Mean \pm SD & \multicolumn{2}{|c|}{$70.58 \pm 8.264$} & \multicolumn{2}{|c|}{$69.29 \pm 8.260$} & \\
\hline $\begin{array}{l}\text { Sex: } \\
\text {-Male } \\
\text {-Female }\end{array}$ & $\begin{array}{l}57 \\
43\end{array}$ & $\begin{array}{l}57.0 \\
43.0\end{array}$ & $\begin{array}{l}57 \\
43\end{array}$ & $\begin{array}{l}57.0 \\
43.0\end{array}$ & 1.000 \\
\hline $\begin{array}{l}\text { Marital status: } \\
\text {-Married } \\
\text {-Widow } \\
\text {-Divorced } \\
\text {-Single }\end{array}$ & $\begin{array}{c}53 \\
42 \\
4 \\
1\end{array}$ & $\begin{array}{c}53.0 \\
42.0 \\
4.0 \\
1.0\end{array}$ & $\begin{array}{c}62 \\
34 \\
4 \\
0\end{array}$ & $\begin{array}{c}62.0 \\
34.0 \\
4.0 \\
0.0\end{array}$ & 0.467 \\
\hline $\begin{array}{l}\text { Level of education: } \\
\text {-Illiterate } \\
\text {-Read and write } \\
\text {-Primary and preparatory } \\
\text { school } \\
\text {-Secondary school } \\
\text { - University education }\end{array}$ & $\begin{array}{c}59 \\
19 \\
12 \\
9 \\
1\end{array}$ & $\begin{array}{l}59.0 \\
19.0 \\
12.0 \\
9.0 \\
1.0\end{array}$ & $\begin{array}{c}58 \\
10 \\
19 \\
11 \\
2\end{array}$ & $\begin{array}{c}58.0 \\
10.0 \\
19.0 \\
11.0 \\
2.0\end{array}$ & 0.189 \\
\hline $\begin{array}{l}\text { Occupation before } \\
\text { retirement: } \\
\text {-Housewife } \\
\text {-Worker (manual and } \\
\text { technical) } \\
\text {-Employee } \\
\text {-Commercial business }\end{array}$ & $\begin{array}{l}37 \\
27 \\
25 \\
11\end{array}$ & $\begin{array}{l}37.0 \\
27.0 \\
25.0 \\
11.0\end{array}$ & $\begin{array}{c}40 \\
31 \\
21 \\
8\end{array}$ & $\begin{array}{c}40.0 \\
31.0 \\
21.0 \\
8.0\end{array}$ & 0.750 \\
\hline $\begin{array}{l}\text { Income: } \\
<400 \\
400- \\
800+\end{array}$ & $\begin{array}{l}55 \\
25 \\
20\end{array}$ & $\begin{array}{l}55.0 \\
25.0 \\
20.0\end{array}$ & $\begin{array}{l}30 \\
32 \\
38\end{array}$ & $\begin{array}{l}30.0 \\
32.0 \\
38.0\end{array}$ & $0.001^{*}$ \\
\hline Mean \pm SD & 516.8 & 292.80 & 599.9 & 299.49 & \\
\hline
\end{tabular}

MCP: Mont Carlo exact probability

* The difference is statistically significant at $\mathrm{p} \leq 0.05$ 
Table (2): Distribution of older adults in the study and control groups according to their health history

\begin{tabular}{|c|c|c|c|c|c|}
\hline \multirow{3}{*}{ Health history } & \multicolumn{4}{|c|}{ Group } & \multirow[b]{3}{*}{ MCP } \\
\hline & \multicolumn{2}{|c|}{ Study } & \multicolumn{2}{|c|}{ Control } & \\
\hline & $\mathrm{n}=\mathbf{1 0 0}$ & $\begin{array}{l}\text { Percent } \\
(\%)\end{array}$ & $\mathrm{n}=\mathbf{1 0 0}$ & $\begin{array}{l}\text { Percent } \\
(\%)\end{array}$ & \\
\hline \multicolumn{6}{|l|}{ Diseases: \# } \\
\hline - CVD & 53 & 53.0 & 44 & 44.0 & 0.203 \\
\hline - Ophthalmological diseases & 32 & 32.0 & 38 & 38.0 & 0.374 \\
\hline - $\mathrm{DM}$ & 20 & 20.0 & 35 & 35.0 & $0.018 *$ \\
\hline - GIT \& hepatic diseases & 12 & 12.0 & 13 & 13.0 & 0.810 \\
\hline - Respiratory diseases & 10 & 10.0 & 4 & 4.0 & 0.096 \\
\hline - Other diseases & 9 & 9.0 & 12 & 12.0 & 0.489 \\
\hline \multicolumn{6}{|l|}{ Medication: \# } \\
\hline - Cardiovascular drugs & 47 & 47.0 & 42 & 42.0 & 0.477 \\
\hline - Diabetic drugs & 19 & 19.0 & 33 & 33.0 & $0.034 *$ \\
\hline - GIT \& hepatic drugs & 12 & 12.0 & 13 & 13.0 & 0.861 \\
\hline - Respiratory drugs & 10 & 10.0 & 3 & 3.0 & $0.027 *$ \\
\hline - Other & 17 & 17.0 & 23 & 23.0 & 0.289 \\
\hline \multicolumn{6}{|l|}{$\begin{array}{l}\text { Family history of hearing } \\
\text { impairment: }\end{array}$} \\
\hline$\bullet \quad$ No & 69 & 69.0 & 86 & 86.0 & \\
\hline - Yes & 31 & 31.0 & 14 & 14.0 & $0.008^{*}$ \\
\hline
\end{tabular}

MCP: Mont Carlo exact probability

\# Multiple Response Variable

$*$ The difference is statistically significant at $\mathrm{p} \leq 0.05$ 
Table (3): Distribution of older adults in the study and control groups according to their social activities

\begin{tabular}{|c|c|c|c|c|c|}
\hline \multirow{3}{*}{ Social activities } & \multicolumn{4}{|c|}{ Group } & \multirow{3}{*}{ МCP } \\
\hline & \multicolumn{2}{|c|}{ Study } & \multicolumn{2}{|c|}{ Control } & \\
\hline & $\mathrm{n}=\mathbf{1 0 0}$ & $\begin{array}{l}\text { Percent } \\
(\%)\end{array}$ & $\mathrm{n}=\mathbf{1 0 0}$ & $\begin{array}{l}\text { Percent } \\
(\%)\end{array}$ & \\
\hline \multicolumn{6}{|l|}{ Live with: } \\
\hline - Spouse & 53 & 53.0 & 62 & 62 & \multirow{4}{*}{0.354} \\
\hline - Children or grand children & 37 & 37.0 & 28 & 28 & \\
\hline - Alone & 5 & 5.0 & 7 & 7.0 & \\
\hline - Relatives & 5 & 5.0 & 3 & 3.0 & \\
\hline \multicolumn{6}{|l|}{ Visits outside home: } \\
\hline - Yes & 39 & 39.0 & 74 & 74.0 & \multirow[t]{2}{*}{$0.001 *$} \\
\hline - No (the cause): & (61) & 61.0 & $(26)$ & 26.0 & \\
\hline -Hearing impairment & 47 & 77.0 & 0 & 0.0 & \multirow[t]{2}{*}{$0.001 *$} \\
\hline -Poor health status or busy & 14 & 23.0 & 26 & 100.0 & \\
\hline \multicolumn{6}{|l|}{ Telephone call: } \\
\hline - Yes & 45 & 45.0 & 70 & 70.0 & \multirow{3}{*}{$0.001 *$} \\
\hline - No (the cause): & $(55)$ & 55.0 & $(30)$ & 30.0 & \\
\hline -Hearing impairment & 45 & 81.8 & 0 & 0.0 & \\
\hline -Inability to use the telephone & 9 & 16.4 & 27 & 90.0 & \multirow{2}{*}{$0.001 *$} \\
\hline -Poor health status or busy & 1 & 1.8 & 3 & 10.0 & \\
\hline \multicolumn{6}{|l|}{ Preference to Sit alone: } \\
\hline - No & 73 & 73.0 & 90 & 90.0 & \multirow{2}{*}{$0.002 * !$} \\
\hline - Yes (the cause) & (27) & 27.0 & (10) & 10.0 & \\
\hline -Hearing impairment & 26 & 96.3 & 0 & 0.0 & \multirow{2}{*}{$0.001 *$} \\
\hline - Poor health status or busy & 1 & 3.7 & 10 & 100.0 & \\
\hline \multicolumn{6}{|l|}{ Watching TV or listening to } \\
\hline - Yes: & 76 & 76.0 & 93 & 93.0 & \multirow{2}{*}{$0.004^{*}$} \\
\hline - No :(the cause): & $(24)$ & 24.0 & (7) & 7.0 & \\
\hline -Hearing impairment & 20 & 83.3 & 0 & 0.0 & \multirow{2}{*}{$0.001 *$} \\
\hline -Poor health status or Busy & 4 & 16.7 & 7 & 100.0 & \\
\hline \multicolumn{6}{|l|}{$\begin{array}{l}\text { Exchange talking with other } \\
\text { when sitting with them: }\end{array}$} \\
\hline - Yes & 86 & 86.0 & 100 & 100.0 & \multirow[t]{4}{*}{$0.001 *$} \\
\hline - No (the cause): & (14) & 14.0 & $(0)$ & 0.0 & \\
\hline -Hearing impairment & 13 & 92.9 & 0 & 0.0 & \\
\hline -Poor health status & 1 & 7.1 & 0 & 0.0 & \\
\hline \multicolumn{6}{|l|}{$\begin{array}{l}\text { Feeling embarrassed when } \\
\text { talking with other for the first }\end{array}$} \\
\hline $\begin{array}{l}\text { talking with other for the first } \\
\text { time: }\end{array}$ & & & & & $0.001 *$ \\
\hline - No & 66 & 66.0 & 97 & 97.0 & \\
\hline - Yes(the cause): & (34) & 34.0 & (3) & 3.0 & $0.001 *$ \\
\hline -Hearing impairment & 34 & 100.0 & 0 & 0.0 & \\
\hline -Poor health status & 0 & 0.0 & 3 & 100.0 & \\
\hline
\end{tabular}

MCP: Mont Carlo exact probability

* The difference is statistically significant at $\mathrm{p} \leq 0.05$ 
Table (4): Distribution of older adults suffering from hearing impairment for the study group according to their history of hearing impairment

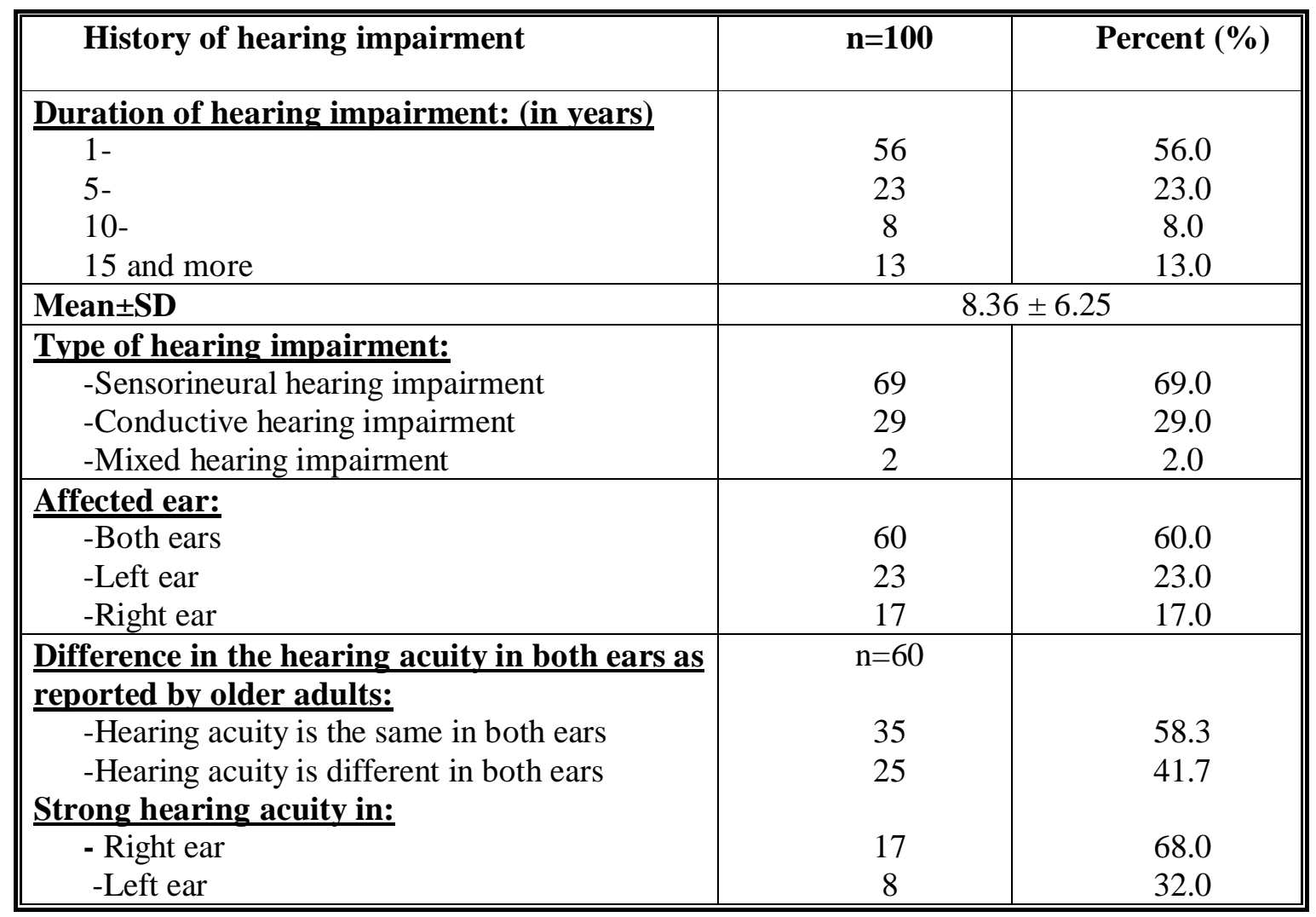

\# Multiple Response Variable 
Table (5): Relation between cognitive, functional and psychosocial status of older adults with hearing impairment and their controls

\begin{tabular}{|c|c|c|c|c|c|}
\hline \multirow{3}{*}{ Item } & \multicolumn{4}{|c|}{ Group } & \multirow{3}{*}{ MCP } \\
\hline & \multicolumn{2}{|c|}{ Study } & \multicolumn{2}{|c|}{ Control } & \\
\hline & $n=100$ & $\begin{array}{c}\text { Percent } \\
(\%)\end{array}$ & $n=100$ & $\begin{array}{c}\text { Percent } \\
(\%)\end{array}$ & \\
\hline $\begin{array}{l}\text { Cognitive status: } \\
\text { Normal cognitive function } \\
\text { Mild cognitive impairment } \\
\text { Severe cognitive impairment }\end{array}$ & $\begin{array}{c}54 \\
39 \\
7 \\
\end{array}$ & $\begin{array}{c}54.0 \\
39.0 \\
7.0 \\
\end{array}$ & $\begin{array}{c}80 \\
17 \\
3 \\
\end{array}$ & $\begin{array}{c}80.0 \\
17.0 \\
3.0\end{array}$ & $0.001 *$ \\
\hline $\begin{array}{l}\text { Activities of daily living: } \\
\text {-independent } \\
\text {-Partially dependent } \\
\text {-Dependent }\end{array}$ & $\begin{array}{c}95 \\
4 \\
1\end{array}$ & $\begin{array}{c}95.0 \\
4.0 \\
1.0\end{array}$ & $\begin{array}{c}94 \\
6 \\
0\end{array}$ & $\begin{array}{c}94.0 \\
6.0 \\
0.0\end{array}$ & 0.594 \\
\hline $\begin{array}{l}\text { Instrumental Activities of Daily } \\
\text { Living: } \\
\text {-Unable to perform activity } \\
\text {-Activity is performed with some } \\
\text { help } \\
\text {-Activity is performed unaided }\end{array}$ & $\begin{array}{l}44 \\
41 \\
15 \\
\end{array}$ & $\begin{array}{l}44.0 \\
41.0 \\
15.0 \\
\end{array}$ & $\begin{array}{l}36 \\
35 \\
29 \\
\end{array}$ & $\begin{array}{l}36.0 \\
35.0 \\
29.0 \\
\end{array}$ & $0.048 *$ \\
\hline $\begin{array}{l}\text { Psychological status: } \\
\text { Severe distress } \\
\text { Moderate distress } \\
\text { Positive well-being }\end{array}$ & $\begin{array}{l}42 \\
25 \\
33\end{array}$ & $\begin{array}{l}42.0 \\
25.0 \\
33.0\end{array}$ & $\begin{array}{c}9 \\
18 \\
73\end{array}$ & $\begin{array}{c}9.0 \\
18.0 \\
73.0\end{array}$ & $0.001 *$ \\
\hline $\begin{array}{l}\text { Social status: } \\
\text { Not lonely } \\
\text { Mild loneliness } \\
\text { Moderate loneliness } \\
\text { Severe loneliness } \\
\text { Extreme loneliness }\end{array}$ & $\begin{array}{c}1 \\
14 \\
60 \\
22 \\
3 \\
\end{array}$ & $\begin{array}{c}1.0 \\
14.0 \\
60.0 \\
22.0 \\
3.0 \\
\end{array}$ & $\begin{array}{c}2 \\
74 \\
23 \\
1 \\
0\end{array}$ & $\begin{array}{c}2.0 \\
74.0 \\
23.0 \\
1.0 \\
0.0 \\
\end{array}$ & $0.001 *$ \\
\hline
\end{tabular}

MCP: Mont Carlo exact probability

* The difference is statistically significant at $\mathrm{p} \leq 0.05$ 


\section{References}

1. Shemesh, R. Hearing impairment: Definitions, assessment and Management. International Encyclopedia of Rehabilitation. 2010. Available at: http://cirrie.buffalo. edu/encyclopedia/en/article/272

2. American Academy of OtolaryngologyHead and Neck Surgery. Cochlear Implants. 2015. Available at: http://www.entnet.org/content/cochleari mplants.

3. World Health Organization. WHO Global Estimates on Prevalence of Hearing Loss: Mortality and Burden of Diseases and Prevention of Blindness and Deafness. Geneva, 2012. Available at:

http://www.who.int/pbd/deafness/news/ GE 65years.pdf.

4. Monahan F, Green C, Marek J, Neighbors $M$ and Sands J. Phipp's Medical-Surgical Nursing. $8^{\text {th }}$ ed. China: Mosby Inc, 2006; 1845-49.

5. Meiner S. Gerontologic Nursing. $4^{\text {th }}$ ed. USA: Mosby Inc, 2011; 636-42.

6. Abdel Hamid O, Khatib O, Aly A, Morad M, Kamel S. Prevalence and Patterns of hearing impairment in Egypt: A national household survey. Eastern Mediterranean Health Journal 2007; 13(5):1170.

7. Mabrouk M. Communication problems of institutionalized elders in Alexandria. Unpublished Master Thesis, Faculty of Nursing. Alexandria University, 2009.

8. El kady H. Prevalence of hearing impairment and its correlates among group of hospitalized chronically ill elderly patients in Alexandria, Egypt. The journal of the Egyptian public health association2012; 87(3,4):57-63.
9. Records of Damanhur National Medical Institute at El-Behaira Governorate (2014).

10. Lewis S, Dirksen S, Heitkemper M, Bucher L, Camera I. Medical-Surgical Nursing: Assessment and Management of Clinical Problem. $8^{\text {th }}$ ed. USA: Mosby Inc, 2011; 428-32.

11. Hinkle J, Cheever K. Brunner and Suddarth's Textbook of MedicalSurgical Nursing. $13^{\text {th }}$ ed. China: Lippincott Co, 2014; 1887-90.

12. AbdElaziz M. Introduction to E.N.T. Faculty of Medicine, Cairo University, 2006; 39-41.

13. El Garem F, El Garem H. El Grem Clear Oto-Rhino -Largynology. $4^{\text {th }}$ ed. Egypt: Alexandria University, 2003; 79-83.

14. New World Encyclopedia. Hearing (sense). Available at: http://www.newworldencyclopedia.org/e ntry/Hearing (sense). Retrieved on: 12/9/2008.

15. Bellman \& Symfon. Your hearing matters. Available at: http://bellman.com/en/yourhearing/facts-about-hearing/.

16. Walling A and Dickson G. Hearing Loss in Older Adults. American Family Physician 2012; 12(85): 1150-6. Available at: http://www.aafp.org/afp/2012/0615/p115 $\underline{0 . h t m l}$

17. Yueh B, Shapiro N, MacLean C, Shekelle P. Screening and Management of Adult Hearing Loss in Primary Care: scientific review. Journal of the American Medical Association 2003; 289(15): 1976-85.

18. Eliopoubs C. Gerontological Nursing. $8^{\text {th }}$ ed. USA: Lippincott Co, 2014; 370-73.

19. Hear it organization. One in sex adults suffer from hearing loss. Available at: 
http://www.hear-it.org/Hearing loss affects one in six.

20. Public Health Agency of Canada. Hearing loss Info-sheet for seniors. 2006. Available at: https://www.google.com.eg/url?sa=t\&rct $=\mathrm{j} \& \mathrm{q}=\& \mathrm{esrc}=\mathrm{s} \&$ source $=$ web $\& \mathrm{~cd}=2 \& \mathrm{ca}$ $\mathrm{d}=$ rja\&uact $=8 \&$ ved $=0$ ahUKEwigqSEof3 KAhXBWRQKHXDwAuwQFggoMAE \&url=http\%3A\%2F\%2Fseniorspolicylen $\underline{s}$.

21. Weinstein E. Aprimer on Hearing Loss in the Eldery. Generations 2003; 27: 1519.

22. Shield B. Evaluation of the Social and Economic Costs of Hearing Impairment. A report For Hear-It 2006:10-20.

23. Miller C. Nursing for Wellness in Older Adults. $6^{\text {th }}$ ed. China: Lippincott Co, 2012;311-30.

24. Folstin J, Folstin S, Hugh M. Mini mental state: Apractical Method of Grading the Cognitive State of Patients for the Clinician. Psychiatric Research 1975; 12: 189-95.

25. Elokl M. Prevalence of Alzheimer Dementia and other Causes of Dementia in Egyptian elderly. Unpublished Master Thesis, Faculty of medicine. Ain Shams University, 2002.

26. Barthel D, Mahoney FI. Functional Evaluation on the Barthel Index. J Marylad State Medical 1965; 14: 56-61.

27. Hallaj F. Activity Patterns of Residents in Elderly Homes. Unpublished Master Thesis, Faculty of Nursing. Alexandria University, 2007.

28. Lawton HP, Brody EM. Assessment of older people: self-maintaining and Instrumental Activities of Daily Living. Gerontologist 1969; 1(19): 179-86.

29. Essayed E. Functional Abilities of Elderly Women with Osteoarthritis and
Their Compliance with Treatment. Unpublished Master Thesis, Faculty of Nursing. Alexandria University, 2007.

30. Dupuy H. Self-representations of General Psychological Well-being of American Adults. Los Angeles, California: Paper presented at American Public Health Association Meeting 1978; 12: 50-2.

31. Dowell I.Measuring Health: A Guide to Rating Scales and Questionnaires. 3rd ed. USA: Oxford University Press, Inc, 2006.

32. Russell D, Cutrona C, Rosa E and York C. Development and Evolution of the ULCA Loneliness Scale, Washington DC: National institute of ageing 1987; 13-64.

ابر اهيم قشقوش "مقياس الاحساس بالوحدة النفسية " .33 1988 كلية التربية جامعة عين شمس الفس "

34. Lin R, Yaffe K, Xia J, Xue L, Harris B, Purchase-Helzner E, Satterfield S, Ayonayon N, Ferrucci L, Simonsick M, Health ABC Study Group F. Hearing Loss and Cognitive Decline in Older Adults. JAMA internal medicine 2013; 173(4):293-9.

35. Crispim K, Ferreira A. Prevalence of self-reported hearing loss and associated risk factors among the elderly in Manaus: a population-based study.Revista CEFAC 2015; 17(6): 1946-56.

36. Gopinatha B, Wang J, Schneider J. Depressive symptoms in older adults with hearing impairments: The Blue Mountains Study. Journal of the American Geriatrics Society 2009; 57:1306-8.

37. Boorsma M, Joling K, Dussel $M$ et al. The incidence of depression and its risk factors in Dutch nursing homes and resident care homes. American Journal of Geriatric Psychiatry 2012; 20:932-42. 
38. Acar B, Yureikli M, Babademez M et al. Effects of hearing aids on cognitive functions and depressive signs in elderly people. Archesof Gerontology and Geriatrics 2011; 52:250-2.

39. Mick P, Kawachi I, Lin F. The association between hearing loss and social isolation in older adults. Otolaryngology--Head and Neck Surgery 2014; 150(3): 378-84.

40. Osborn K, Wraa C, Watson A. Medical Surgical Nursing Preparation for Practice .USA: Pearson Education Inc, 2010; 2303-18.

41. Stevens G, Flaxman S, Brunskill E, Mascarenhas M, Mathers C, Finucane M.Global and regional hearing impairment prevalence: an analysis of 42 studies in 29 countries. The European Journal of Public Health 2013; 23(1): 146-52.

42. Schacht J, Talaska A, Rybak L.Cisplatin and aminoglycoside antibiotics: hearing loss and its prevention. The anatomical record 2012; 295(11): 1837-50.

43. Sogebi O. Assessment of the risk factors for hearing loss in adult Nigerian population. Nigerian medical journal: journal of the Nigeria Medical Association 2013; 54(4): 244. 